\title{
Predictors of nonadherence with blood pressure regimens in hemodialysis
}

This article was published in the following Dove Press journal:

Patient Preference and Adherence

20 September 2013

Number of times this article has been viewed

\section{Zorica Kauric-Klein \\ College of Nursing, Wayne State University, Detroit, MI, USA}

Correspondence: Zorica Kauric-Klein College of Nursing, Wayne State University, 5557 Cass Avenue,

Detroit, MI 48202, USA

Email ai6191@wayne.edu
Background: Hypertension is very poorly controlled in patients on hemodialysis (HD). Demographic and psychosocial predictors of nonadherence with blood pressure (BP) regimens in HD have not been investigated. A study of $118 \mathrm{HD}$ patients from six outpatient HD units was conducted to determine the relationship between demographic/psychosocial factors and adherence with BP-related regimens, ie, fluid restriction, BP medication adherence, and HD treatment adherence.

Methods: Descriptive statistics, Pearson correlations, and multiple regressions were conducted to analyze and determine the relationships between variables.

Results: Younger age was related to increased fluid gains $(r=-0.37, P<0.01)$, decreased medication adherence $(r=-0.19, P=0.04)$, increased missed HD treatments $(r=-0.37, P<0.01)$, and diastolic BP $(r=-0.60, P<0.01)$. Female sex was significantly related to decreased fluid gains $(r=-0.28, P<0.01)$. Race was related to increased missed HD treatments $(r=0.22$, $P=0.02)$. Increased social support was related to decreased missed HD treatments $(r=-0.22$, $P=0.02)$. Depression scores were inversely related to decreased medication adherence scores $(r=0.24, P=0.01)$.

Conclusion: By identifying risk factors for nonadherence with BP-related regimens (young age, male sex, decreased social support, and depression), health care providers can plan early clinical intervention to minimize the risk of nonadherence.

Keywords: nonadherence, hemodialysis, blood pressure, demographic predictors, psychosocial predictors

\section{Introduction}

Cardiovascular disease accounts for almost $50 \%$ of deaths in patients with renal disease. ${ }^{1}$ Hypertension is a major risk factor for cardiovascular disease in end-stage renal disease. ${ }^{2}$ The prevalence rate of hypertension in patients on chronic hemodialysis (HD) is approximately $75 \%-100 \% .^{1,3,4}$ According to the National Kidney Foundation Kidney Disease Outcomes Quality Initiative (K/DOQI, 2005) clinical practice guidelines, predialysis and post dialysis blood pressure (BP) should be less than $140 / 90 \mathrm{mmHg}$ and less than $130 / 80 \mathrm{mmHg}$, respectively. ${ }^{5}$

The literature indicates that the major reasons for uncontrolled hypertension in this population include excess salt and fluid intake, nonadherence with BP medications, and missing HD treatments. ${ }^{4,6,7}$ Nonadherence with fluid restrictions and missing HD treatments can result in fluid overload and elevated BP. Estimates of nonadherence with fluid restrictions in HD range from $30 \%$ to $74 \%{ }^{5,8,9}$ Estimates of patients missing HD treatments range from $0 \%$ to $35 \% .{ }^{9,10}$ The literature indicates 
that $25 \%-50 \%$ of HD patients are nonadherent with BP medication regimens, a trend associated with poor control of BP in these patients. ${ }^{8,11}$

A review of the literature did not find potential predictors specific to nonadherence with BP regimens in HD. However, the literature did reveal predictors associated with nonadherence with other self-care behaviors related to HD. In a large-scale study of chronic outpatient HD patients $(n=1,230)$, Bame et $\mathrm{al}^{12}$ found that half of the participants did not adhere with instructions for taking medication $(50.2 \%)$ or for fluid restriction $(49.5 \%)$. Younger patients were much less adherent with instructions for taking medications than elderly patients. According to Bame et al, ${ }^{12}$ age was directly related to fluid restriction adherence $(P<0.01)$, with adherence increasing 1.4 times for every 10 -year increase in age. Males were two thirds less likely to adhere with fluid intake recommendations. Kugler et $\mathrm{al}^{13}$ also found significant correlations between young age and fluid restriction nonadherence $(P=0.001)$ in a sample of 916 chronic HD patients in Germany and Belgium.

Saran et $\mathrm{al}^{14}$ identified predictors of nonadherence in a large sample of HD patients $(n=7,676)$. The sample was drawn from the Dialysis Outcomes and Practice Patterns Study database and included participants from Japan, the US, and five European countries. Younger age was significantly related to skipping or shortening HD treatments and excessive interdialytic weight gain (IDWG). Race was related to skipping and shortening treatments, with African Americans missing more HD treatments than other ethnic groups. Depression was also related to skipping and shortening HD treatments.

Leggat et $\mathrm{al}^{10}$ conducted a study in 6,251 chronic HD patients to determine predictors and outcomes of nonadherence. The strongest predictor was age, with those aged 20-39 years being the least adherent with most measures (eg, IDWG, missing and shortening treatments). Sex, length of time on HD, and diabetes were not good predictors of nonadherence. Race, however, was related to skipping treatments, with African Americans skipping and shortening more treatments than other ethnic groups. ${ }^{10}$

Low income was associated with nonadherence to HD behaviors, while positive correlations were found between education and adherence with HD regimens. ${ }^{12}$ Social support was related to adherence with HD regimens in a number of studies. ${ }^{14-16}$ However, Kugler et al ${ }^{13}$ did not find a relationship between social support and HD adherence behaviors. A number of studies found a relationship between depression and poor adherence with HD-related regimens. ${ }^{17-20}$

In conclusion, a review of the literature found that the most frequently cited demographic predictors of nonadherence with HD behaviors were young age, male sex, and race. Relationships have also been found between a number of psychosocial variables (depression, social support, income) and adherence behaviors in the HD population.

The major aim of one randomized, controlled study ${ }^{21}$ was to determine if an intervention incorporating self-regulation components (monitoring, goal setting, and reinforcement) could improve BP control in a chronic HD population. Using the study data as a secondary source, the major purpose of this paper was to determine if there were relationships between demographic/psychosocial factors (age, sex, race, education, income, comorbidities, social support, and depression) and adherence with BP-related regimens (fluid intake, medication, and HD adherence).

\section{Materials and methods Study population}

A 90-day, randomized, controlled study was conducted to determine if an intervention incorporating monitoring, goal setting, and reinforcement could improve BP control in a chronic HD population. A potential sample of 836 participants was drawn from six HD units in Michigan, and 118 participants completed the study. Eligibility criteria for the study included: age $>18$ years; a 4-week average pre-HD BP $>150 \mathrm{mmHg}$ or diastolic $\mathrm{BP}>90 \mathrm{mmHg}$; and ability to read and speak English. Exclusion criteria included: having been on HD for less than 6 months; history of illicit drug use; history of mental illness; lack of orientation to person, time, or place; and a major health problem, such as terminal cancer or human immunodeficiency virus.

The study was approved by the institutional review board of a US Midwest research university and the HD units. The nurse manager, medical director, and staff of the HD facilities attended an in-service on the study led by the principal investigator. Next, interested participants were identified by the medical director and/or nursing staff. The principal investigator explained the study in detail to the potential participants and answered all questions. Potential participants were then asked to sign a written consent form approved by the institutional review board.

After collecting the written consent forms, the principal investigator reviewed charts and flow sheets to verify eligibility criteria. Demographic data and medical history data were obtained by the principal investigator from the participants' 
medical charts. Baseline data collection also included Modified Mini Mental State Examination and Patient Health Questionnaire (PHQ-9) scores. In order to determine if participants met the inclusion criteria related to cognitive ability, the Modified Mini Mental State Examination was used to measure global cognitive function. Depression was measured using the nine-item PHQ-9. Subjects who scored less than 80 on the Modified Mini Mental State Examination or greater than 15 on the PHQ-9 did not meet the criteria for inclusion in the study. For those who met the inclusion criteria, the ENRICHD Social Support Instrument and the Morisky Scale were administered.

\section{Measurement tools}

\section{Social support}

Social support was measured using the ENRICHD Social Support Instrument, a self-administered seven-item questionnaire that primarily measures functional social support, especially emotional support, and has been used primarily in cardiac patients. ${ }^{22}$ Possible scores can range from 8 to 34 , with higher scores indicating greater social support. Reliability and validity have been established in a sample of 196 patients post myocardial infarction. ${ }^{22}$

\section{Depression}

Depression was measured using the nine-item, 5-minute PHQ-9. A score of 10 indicates minor depression, 11-14 indicates mild depression, and a score $>15$ indicates major depression. The tool has been tested and validated in the HD population. ${ }^{23}$ The PHQ-9 was administered at baseline and 12 weeks.

\section{Medication adherence}

Adherence with the BP medication regimen was measured using the Morisky Scale, ${ }^{24}$ a four-item instrument with dichotomous (yes/no) response options. The sum of "yes" responses provides a total score of nonadherence. Patients who scored "no" on all questions were classified as highly adherent and those who answered "yes" on at least one question were classified as having medium or low adherence. This scale has been validated and found to be reliable in a variety of medication adherence studies. ${ }^{25-27}$ The Morisky Scale was administered at baseline and 12 weeks.

\section{HD adherence}

To determine adherence with HD regimens, HD records were reviewed to calculate the number of HD treatments missed over 12 weeks.

\section{Interdialytic weight gain}

Dialysis flow sheets were reviewed by the investigator at baseline (30 days), 12 weeks (completion of intervention), and 16 weeks (4 weeks post intervention) in order to determine IDWG. Patients were weighed in the HD unit before and after their HD treatments. IDWGs were calculated by subtracting the patient's weight after their last HD treatment from weight before the next HD treatment. Three IDWGs were averaged in order to determine mean (M) weekly IDWG.

\section{Blood pressure}

Average BPs were calculated from the HD flow sheets. PreHD BPs were averaged to determine mean BP at baseline, 12 weeks and 16 weeks.

\section{Statistical analysis}

Demographic and questionnaire data were coded and entered into Statistical Package for the Social Sciences version 17 software (SPSS Inc., Chicago, IL, USA) by the investigator. Descriptive statistics were used to analyze all study variables. Pearson correlations and multiple regression were conducted to determine relationships between demographic/psychosocial variables and BP-related regimens (fluid restriction, medication adherence, and HD adherence).

\section{Results}

\section{Baseline characteristics}

Table 1 summarizes the baseline characteristics of the sample $(n=118)$. The average age of the participants was $59.69 \pm 15.98$ years with a range of $19-91$ years. There were $60(51 \%)$ men and $58(49 \%)$ women. The race composition consisted of 101 (86\%) African Americans, 14 Caucasians (12\%), and three Middle Eastern (2.5\%) participants. For the entire sample, the average span of education was $12.43 \pm 2.3$ years with a range of 3-20 years. In terms of income, $58(49.2 \%)$ of the participants had a total yearly household income of less than $\$ 10,000$, which is considered below the poverty level. The majority were unemployed $(\mathrm{n}=99,83.9 \%)$, approximately 15 (13\%) were employed on a part-time basis, and only four (3.3\%) were employed on a full-time basis.

In terms of being married or living with a partner, $74(63 \%)$ participants indicated that they were not married and $44(37 \%)$ were married or living with a partner. In terms of comorbidities, approximately $50 \%$ of the sample participants had diabetes. Thirty-eight (32\%) had type 1 diabetes and $21(17.8 \%)$ had type 2 diabetes. Forty (34\%) had atherosclerotic heart disease and 28 (24\%) had congestive heart 
Table I Demographic variables $(\mathrm{n}=1 \mid 8)$

\begin{tabular}{llll}
\hline Variable & $\mathbf{n}$ & $\%$ & Mean (SD) \\
\hline Age (years) & & & 59.7 (I5.9) \\
$19-39$ & 15 & 12 & \\
$40-49$ & 12 & 10 & \\
$50-59$ & 31 & 28 & \\
$60-69$ & 27 & 23 & \\
$>70$ & 34 & 27 & \\
Sex & & & \\
Male & 60 & 51 & \\
Female & 58 & 49 & \\
Race & & & \\
African American & 101 & 86 & \\
White & 14 & 12 & \\
Middle Eastern & 3 & 2.5 & \\
Education & & & \\
$\quad<$ Grade 8 & 6 & 5 & \\
Some high school & 26 & 22 & \\
High school graduate & 30 & 25.4 & \\
Some college & 41 & 35 & \\
College graduate & 15 & 12.7 \\
Employment & & & \\
Not employed & 99 & 83.9 \\
Part-time & 15 & 12.7 \\
Full-time & 4 & 3.3 \\
Married or living with a partner & & & \\
Yes & 44 & 37 & \\
No & 74 & 63 & \\
\hline
\end{tabular}

Abbreviation: SD, standard deviation.

disease. Sixty-four participants (54\%) were taking three or more BP medications. Total medications taken by the participants ranged from zero to six.

\section{Psychosocial factors and HD adherence} Social support

The average mean social support score for the sample was $29.3 \pm 4.8$, with a range of scores from 9 to 38 .

\section{Depression}

The total mean depression score for the sample was $10.97 \pm 1.60$, with scores ranging from 4 to 14 . At 12 weeks, the total mean depression score decreased slightly to 10.75, with scores ranging from 9 to 14 . According to the depression assessment tool used for this study (PHQ-9), the sample score indicated a mild level of depression. There was no significant difference in scores between baseline and 12 weeks $(P=0.07)$.

\section{BP medication adherence}

Medication adherence scores ranged from zero (100\% adherence) to four (maximum nonadherence), with an average mean score of $0.8 \pm 0.97$ at baseline and
$0.88 \pm 1.1$ at 12 weeks. According to the Morisky Scale, these results indicate a medium level of medication adherence. There was no significant difference in scores between baseline and 12 weeks $(P=0.29)$.

\section{HD attendance}

The overall mean number of missed HD treatments was $1 \pm 1.4$, with a range of $0-6$.

\section{Fluid gains}

Average IDWG for the sample was $2.5 \pm 1.0 \mathrm{~kg}$ at baseline, and $2.5 \pm 1.1 \mathrm{~kg}$ at 12 weeks and $2.4 \pm 1.1 \mathrm{~kg}$ at 16 weeks. IDWG ranged from $0.10 \mathrm{~kg}$ to $6.7 \mathrm{~kg}$. Average fluid gains were not significantly different from baseline to 12 weeks.

\section{Blood pressure}

At baseline, mean systolic BP for the group was $163.6 \pm 12.4 \mathrm{mmHg}$, with a range of $142-202 \mathrm{mmHg}$, and mean diastolic BP was $87.4 \pm 10.2 \mathrm{mmHg}$, with a range of 64-119 mmHg. The average systolic BP decreased significantly from $163.6 \mathrm{mmHg}$ at baseline to $158.5 \pm 12.5 \mathrm{mmHg}$ at 12 weeks $(P<0.01)$. The average diastolic BP decreased significantly from $87.4 \mathrm{mmHg}$ at baseline to $85.3 \pm 10.4 \mathrm{mmHg}$ at 12 weeks $(P<0.01)$.

\section{Relationships between demographic/ psychosocial variables and BP-related regimens}

Tables 2 and 3 identify the correlations between demographic/ psychosocial variables and adherence with BP-related regimens.

\section{Fluid gains}

Age was inversely related to fluid gains at baseline and at 12 weeks and 16 weeks, indicating that elderly individuals

Table 2 Correlations between demographic/psychosocial variables and IDWG $(n=118)$

\begin{tabular}{llll}
\hline Variable & $\begin{array}{l}\text { Baseline } \\
\text { IDWG }\end{array}$ & $\begin{array}{l}\text { I 2-week } \\
\text { IDWG }\end{array}$ & $\begin{array}{l}\text { I6-week } \\
\text { IDWG }\end{array}$ \\
\hline Age & $-0.34^{* *}$ & $0.37^{* *}$ & $-0.34^{* *}$ \\
Sex & $0.19^{*}$ & $-0.28^{* *}$ & -0.14 \\
Education & 0.08 & 0.15 & 0.1 I \\
Race & -0.04 & -0.04 & -0.04 \\
Income & -0.06 & 0.03 & -0.04 \\
Total comorbidities & -0.04 & -0.01 & -0.03 \\
Social support & -0.03 & & \\
Depression & -0.24 & -0.03 & \\
\hline
\end{tabular}

Notes: $* P<0.05$; **P $<0.001$

Abbreviation: IDWG, interdialytic weight gain. 
Table 3 Correlations between demographic/psychosocial variables, medication adherence and missed HD treatments $(n=118)$

\begin{tabular}{llll}
\hline Variable & $\begin{array}{l}\text { Baseline } \\
\text { Morisky } \\
\text { scale score }\end{array}$ & $\begin{array}{l}\text { I 2-week } \\
\text { Morisky } \\
\text { scale score }\end{array}$ & $\begin{array}{l}\text { Missed HD } \\
\text { treatment }\end{array}$ \\
\hline Age & $-0.19^{*}$ & $-0.29 * *$ & $-0.39 * *$ \\
Sex & 0.02 & -0.15 & -0.12 \\
Education & 0.03 & -0.03 & -0.05 \\
Race & 0.16 & 0.18 & $0.22^{*}$ \\
Income & -0.09 & 0.04 & -0.04 \\
Total comorbidities & $0.23^{*}$ & 0.12 & 0.03 \\
Social support & 0.05 & 0.18 & $-0.22^{*}$ \\
Depression & $0.24 * *$ & $0.20^{*}$ & 0.05 \\
\hline
\end{tabular}

Notes: $* P<0.05 ; * * P<0.001$.

Abbreviation: $\mathrm{HD}$, hemodialysis.

consumed less fluid. Sex was found to be inversely related to fluid gains at baseline $(r=0.19, P<0.05)$ and 12 weeks ( $r=-0.28, P<0.01$ ) indicating that females gained less fluid than males. Females gained an average $2.2 \mathrm{~kg}$ of fluid between HD treatments and males gained an average of $2.8 \mathrm{~kg}$. Sex was related to diastolic BP $(r=-0.23, P=0.01)$, with males having higher diastolic BPs than females. Baseline and 12-week depression scores were inversely correlated with fluid gains ( $r=-0.24, P=0.01$ ), with males having higher diastolic BPs than females. Multiple regression was conducted to determine the variables that predicted the greatest variance in IDWG. The linear combination of age and sex was significantly related to IDWG at baseline $[F(1,116)=15.56, P<0.01]$. The multiple correlation coefficient was 0.34 , indicating that $12 \%$ of the variance in IDWG was explained by age and sex.

\section{Medication adherence}

Age was also significantly correlated with baseline medication adherence $(r=-0.186, P=0.04)$, and 12-week medication adherence scores $(r=-0.29, P=0.002)$, indicating that the elderly were more adherent with BP medication regimens. Total comorbidities were related to baseline medication adherence in the overall sample $(r=0.23$, $P=0.01$ ), indicating that increased comorbidities resulted in decreased medication adherence. However, no significant relationship was found between total comorbidities and 12-week medication adherence scores. Depression scores were correlated with baseline medication adherence scores $(r=0.24, P<0.01)$ and 12 -week medication adherence scores $(r=0.20, P<0.05)$.

\section{Missed HD treatments}

Age was also found to be inversely related to missed HD treatments $(r=-0.37, P<0.01)$ and diastolic BP $(r=-0.60, P<0.01)$.
Race was related to missed HD treatments $(r=0.22$, $P<0.01)$, with African Americans missing more HD treatments $(M=1.2)$ than Caucasians $(M=0.29)$. Decreased social support was significantly related to increased missed HD treatments in the overall sample $(r=0.22, P=0.02)$. A significant inverse relationship was found between decreased social support and increased diastolic BP ( $r=-0.37, P<0.01)$. Correlations were also found between medication adherence $(r=0.22, P=0.02)$ and missed HD treatments, indicating that nonadherence in one area of BPrelated regimens was related to other nonadherent behavior. Total missed HD treatments were related to increased fluid gains $(r=0.26, P<0.01)$.

\section{Relationships between BP-related regimens and $\mathrm{BP}$}

Correlations were also conducted to determine if there were significant relationships between BP-related regimens (fluid gains, medication adherence, and missed HD treatments) and BP (Table 4). Significant relationships were found between medication adherence and average systolic BP $(r=0.20$, $P=0.03)$ and average diastolic BP $(r=0.45, P<0.01)$. Average fluid gains were also found to be significantly related to average diastolic BP $(r=0.20, P=0.027)$. Total missed HD treatments were found to be significantly correlated with both average systolic BP $(r=0.32, P=0.001)$ and diastolic $\mathrm{BP}(r=0.45, P<0.01)$.

\section{Discussion}

Significant relationships were found between adherence with BP regimens and BP. Decreased BP medication adherence and missed HD treatments were significantly related to increased systolic BP. Increased fluid gains, decreased BP medication adherence, and increased missed HD treatments were all found to be significantly related to diastolic BP. These findings are supported in the literature. ${ }^{5,8-11}$

Age was inversely related to fluid gains, concurrent with the literature. ${ }^{9,10,16}$ In a large study conducted by Leggat et al, ${ }^{10}$ the strongest predictor of noncompliance with fluid restriction was younger adult age. Older adults adhered more to other

Table 4 Correlations between blood pressure and blood pressure-related regimens

\begin{tabular}{llll}
\hline $\begin{array}{l}\text { Blood } \\
\text { pressure }\end{array}$ & $\begin{array}{l}\text { Fluid } \\
\text { gain }\end{array}$ & $\begin{array}{l}\text { Medication } \\
\text { adherence }\end{array}$ & $\begin{array}{l}\text { Hemodialysis } \\
\text { adherence }\end{array}$ \\
\hline Systolic & 0.09 & $0.20^{*}$ & $0.32^{* *}$ \\
Diastolic & $0.20^{*}$ & $0.26^{* *}$ & $0.45^{* *}$ \\
\hline
\end{tabular}

Notes: $* p<0.05$; $* * p<0.001$. 
BP-related regimens, including decreased missed HD treatments and increased medication adherence. The literature supports age as a factor in HD regimen adherence. ${ }^{27} \mathrm{~A}$ possible explanation is that older adults may have been on HD for a longer period of time compared with younger patients, and may have adapted to the self-care behaviors needed for HD regimens. Other explanations include older HD patients being more concerned with their mortality and leading more structured lives that are conducive to hemodialysis. ${ }^{28}$ It is also possible that younger age groups are nonadherent with fluid intake guidelines due to the stress of being on HD, while trying to manage multiple family and work obligations. Younger patients may also have more difficulty accepting that they have a chronic disease.

In the present study, females consumed less fluid than males, a finding supported in the literature. ${ }^{10,12,28,29}$ Race was related to missed HD treatments, similar to the findings found in the Dialysis Outcomes and Practice Patterns Study, which found a higher incidence of skipping and shortening HD treatments among African Americans. ${ }^{14}$ In the present study, no relationship was found between education and adherence with BP regimens. Leggat et $\mathrm{al}^{10}$ found similar results in their study of 6,251 HD patients; that there was no relationship between higher education level, levels of IDWG, or missing and skipping HD treatments.

Social support was inversely related to missed HD treatments and diastolic BP in this sample. These findings are consistent with reports in the literature. $\mathrm{O}^{\prime} \mathrm{Brien}^{30}$ found social support to be related to improved adherence to HDrelated self-care behaviors in a sample of 126 patients in an urban US outpatient HD setting. Other studies have also found that social support has a positive effect on adherence with self-care regimens. ${ }^{31-33}$

Baseline depression levels were correlated with decreased average IDWG $(r=-0.24, P=0.01)$. This finding is also supported in the literature. ${ }^{16,34}$ Depression was correlated with decreased medication adherence at baseline $(r=0.24$, $P=0.01)$, and at 12 weeks ( $r=0.20, P=0.03)$ Similar results were described by Cukor et al, ${ }^{17}$ who found a significant correlation between depression and decreased medication adherence in a sample of 65 HD patients and 94 kidney transplant patients. Rosenthal et $\mathrm{al}^{35}$ also found a significant relationship between depression and medication adherence ( $r=-0.49, P<0.01)$ in a sample of $130 \mathrm{HD}$ patients.

In the present study, type 1 and type 2 diabetics had slightly greater IDWG than nondiabetics; however, the differences were not significant. These findings concur with reports in the literature. Brady et $\mathrm{al}^{36}$ and Leggat et $\mathrm{al}^{10}$ found that the comorbid condition of diabetes was associated with increased IDWG. A possible explanation for this finding is that hyperglycemia may trigger the thirst response in diabetics, which increases fluid consumption.

This study had a number of strengths. It is the first to investigate the relationship between demographic/ psychosocial factors and adherence with BP-related behaviors in HD. It also measured adherence behavior over more than one time period.

One of the weaknesses of the study was its use of selfreport tools (ie, the Morisky Scale, PHQ-9, and ENRICHD Social Support Instrument and Social Support scale). Bias can occur with self-report measures because patients tend to consistently overestimate their adherence behaviors. Another limitation was only using the Morisky Scale to assess for medication adherence. Future studies should use the Morisky Scale in addition to other assessment methods of medication adherence, such as pill counts, prescription refills, and electronic monitoring in order to improve the reliability and validity of findings. Another weakness was the sample composition, which was predominantly African American (86\%), and does not reflect the current US HD population. Future studies need to be conducted with samples that represent the demographic balance of the US HD population.

\section{Conclusion}

A number of important findings emerged from this study. Younger age was found to be related to increased fluid gains ( $r=-0.37, P<0.01)$, decreased medication adherence ( $r=-0.186, P=0.04)$, increased missed HD treatments $(r=-0.37, P<0.01)$, and diastolic BP $(r=-0.60, P<0.01)$. Sex was found to be significantly related to decreased fluid gains $(r=-0.28, P<0.01)$. Race was related to increased missed HD treatments $(r=0.22, P=0.02)$. Increased social support was related to decreased missed HD treatments ( $r=-0.22, P=0.02)$. Depression scores were inversely related to decreased medication adherence scores $(r=0.24$, $P=0.01)$.

The results of this study have a number of implications. By identifying some of the risk factors related to nonadherence with BP regimens in the HD patient, health care providers can plan early clinical interventions to minimize the risk of nonadherence. Further studies need to be conducted to explore and understand the reasons why young African American males appear to be the least adherent with BPrelated regimens. Based on this knowledge, more effective interventions can be implemented to improve adherence. Interventions also need to be tailored to individuals with 
low social support in order to improve adherence with BPrelated regimens. The study also clearly demonstrates the importance of assessment and treatment of depression in the HD population in order to improve adherence with a number of HD-related adherence behaviors.

\section{Disclosure}

The author reports no conflicts of interest in this work.

\section{References}

1. US Renal Data System. USRDS 2010 Annual Data Report: Atlas of End-Stage Renal Disease in the United States. Bethesda, MD: National Institutes of Health, National Institute of Diabetes and Digestive and Kidney Diseases; 2010.

2. Fagugli RM, Taglioni C, Rossi D, Ricciardi D. The impact of hypertension in hemodialysis patients. Curr Hypertens Rev. 2008;4:100-106.

3. Agarwal R, Nissenson LA, Bataille D, Coyne D, Trout J, Warnock D. Prevalence, treatment and control of chronic hemodialysis patients in the United States. Am J Med. 2003;115:291-297.

4. Horl M, Horl W. Hemodialysis-associated hypertension: pathophysiology and therapy. Am J Kidney Dis. 2002;39:227-244.

5. National Kidney Foundation. KDOQI clinical practice guidelines on hypertension and antihypertensive agents in chronic kidney disease. Am J Kidney Dis. 2004;43 Suppl 1:S1-S290.

6. Agarwal R. Role of home blood pressure monitoring in hemodialysis patients. Am J Kidney Dis. 1999;33:682-687.

7. Rahman M, Dixit A, Donley V, et al. Factors associated with inadequate blood pressure control in hypertensive hemodialysis patients. Am J Kidney Dis. 1999;33:498-506.

8. Curtin RB, Svarstad BL, Keller TH. Hemodialysis patients' noncompliance with oral medications. Nephrol Nurs J. 1999;26:307-316.

9. Rahman M, Fu P, Sehgal AR, Smith MC. Interdialytic weight gain, compliance with dialysis regimen, and age are independent predictors of blood pressure in hemodialysis patients. Am J Kidney Dis 2000;35:257-265.

10. Leggat J, Orzol S, Hulbert-Shearon T, Golper T, Jones C, Held P Noncompliance in hemodialysis predictors and survival analysis. Am J Kidney Dis. 1998;32:139-145.

11. Rahman M, Griffin V. Patterns of antihypertensive use in hemodialysis patients. Am J Health Syst Pharm. 2004;61:1473-1478.

12. Bame SI, Petersen N, Wray NP. Variation in hemodialysis patient compliance according to demographic characteristics. Soc Sci Med. 1993;37:1035-1043

13. Kugler C, Vlaminck H, Haverich A, Maes B. Nonadherence with diet and fluid restrictions among adults having hemodialysis. $J$ Nurs Scholarsh. 2005;37:25-29.

14. Saran R, Bragg-Gresham J, Rayner van Dijk, et al. Non adherence in hemodialysis: associations with mortality, hospitalization and practice patterns in the DOPPS. Kidney Int. 2003;64:254-262.

15. Christensen A, Wiebe J, Edwards D, Michels J, Lawton W. Body consciousness, illness-related impairment and patient adherence in hemodialysis. J Consult Clin Psychol. 1996;64:147-152.

16. Sensky T, Leger C, Gilmour S. Psychosocial and cognitive factors associated with adherence with dietary and fluid restriction regimens by people on chronic haemodialysis. Psychother Psychosom. 1996;61: $36-42$.
17. Cukor D, Rosenthal DS, Jindal RM, Brown CD, Kimmel PL. Depression is an important contributor to low medication adherence in hemodialyzed patients and transplant recipients. Kidney Int. 2009;75:1223-1229.

18. Kaveh K, Kimmel P. Compliance in hemodialysis patients: multidimensional measures in search of a gold standard. Am J Kidney Dis. 2001;37:244-266.

19. Kimmel P. Depression in patients with chronic renal disease: what we know and what we need to know. $J$ Psychosom Res. 2002;53: 951-956.

20. Taskapan H, Ates F, Kaya B, et al. Psychiatric disorders and large interdialytic weight gain in patients on chronic haemodialysis. Nephrology. 2005;10:15-20.

21. Kauric-Klein Z. Improving blood pressure control through a supportive educative nursing intervention. Nephrol Nurs J. 2012;39:217-218.

22. Mitchell PH, Powell L, Blumenthal J. A short social support measure for patients recovering from myocardial infarction: the ENRICHD social support inventory. J Cardiopulm Rehabil. 2003;23:398-403.

23. Watnick S, Wang P, Demandura T, Ganzini L. Validation of two depression screening tools in dialysis patients. Am J Kidney Dis. 2005;46: 919-924.

24. Morisky D, Green L, Levine DM. Concurrent and predictive validity of a self-reported measure of medication adherence. Med Care. 1986;24: 67-74.

25. Krapek K, King K, Warren S, George K, Caputo D, Mihelich K. Medication adherence and associated hemoglobin $\mathrm{A}_{1 \mathrm{c}}$ in type 2 diabetes. Ann Pharmacother. 2004;38:1357-1362.

26. Sung JC, Nichol MB, Venturini F, Bailey KL, McCombs JS, Cody M. Factors affecting patient compliance with antihyperlipidemic medications in an HMO population. Am J Manag Care. 1998;4: 1421-1430.

27. Patel R, Taylor S. Factors affecting medication adherence in hypertensive patients. Ann Pharmacother. 2002;36:40-45.

28. Boyer C, Friend R, Chlouverakis G, Kaloyanides G. Social support and demographic factors influencing compliance of hemodialysis patients. J Appl Soc Psychol. 1990;20:1902-1918.

29. Arici M, Altun V, Usalan C, et al. Compliance in hemodialysis patients. Unanticipated monitoring of biochemical indices. Blood Purif. 1999; $16: 275-280$

30. O'Brien M. Compliance behavior and long-term maintenance dialysis. Am J Kidney Dis. 1990;15:209-214.

31. Christensen AJ, Smith TW, Turner CW, Holman JM, Gregory MC, Rich MA. Family support, physical impairment, and adherence in hemodialysis: an investigation of main and buffering effects. Behav Med. 1992;15:313-325.

32. Mai F, Busby K, Bell R. Clinical rating of compliance in chronic hemodialysis patients. Can J Psychiatry. 1999;44:478-482.

33. Oka M, Chaboyer W. Dietary behaviors and sources of support in hemodialysis patients. Clin Nurs Res. 1999;8:302-317.

34. Everett K, Stetten C, Carmack C, Brantley P, Jones G, McKnight R. Predicting noncompliance to fluid restrictions in hemodialysis patients. Dial Transplant. 1993;22:614-620.

35. Rosenthal Asher D, Ver Halen N, Cukor D. Depression and nonadherence predict mortality in hemodialysis treated end-stage renal disease patients. Hemodial Int. 2012;16:387-393.

36. Brady BA, Tucker CM, Alfino PA, Tarrant DG, Finlayson GC. An investigation of factors associated with fluid adherence among hemodialysis patients: a self-efficacy theory based approach. Ann Behav Med. 1997; 19:339-343 
Patient Preference and Adherence

Dovepress

\section{Publish your work in this journal}

Patient Preference and Adherence is an international, peer-reviewed, open access journal focusing on the growing importance of patient preference and adherence throughout the therapeutic continuum. Patient satisfaction, acceptability, quality of life, compliance, persistence and their role in developing new therapeutic modalities and compounds to

optimize clinical outcomes for existing disease states are major areas of interest. This journal has been accepted for indexing on PubMed Central. The manuscript management system is completely online and includes a very quick and fair peer-review system. Visit http://www.dovepress.com/ testimonials.php to read real quotes from published authors.

Submit your manuscript here: http://www.dovepress.com/patient-preference-and-adherence-journal 